\title{
Respuesta agradecida a las reseñas de Mirka Torres y Virginia Trevignani.
}

\author{
Cecilia Güemes \\ Centro de Estudios Políticos y Constitucionales \\ cecilia.guemes@cepc.es
}

DOI: https://doi.org/10.20318/eunomia.2017.3660

Comienzo esta intervención agradeciendo la generosidad de Isabel Wences y el equipo editorial de Eunomía al facilitarnos este espacio tan singular y apropiado para presentar y discutir sobre la confianza social en Latinoamérica.

Los comentarios de Mirka Torres y Virginia Trevignani conducen a temas de interés para la ciencia política y la sociología actual que en mi trabajo están marginalmente tratados y auguran, sin lugar a dudas, futuros trabajos. Mi gratitud hacia ellas.

La reseña de Torres tiene varias virtudes, la primera, traer a colación tres grandes temas que preocupan y son actuales a la región como son: la articulación entre los mecanismos de deliberación y participación y la democracia representativa; la incidencia del capital social en la regeneración democrática, la urgencia de ocuparse de estos temas tomando como objeto la realidad y complejidad latinoamericana. La segunda, esbozar una insuficiencia del trabajo, la investigadora echa en falta una exégesis y tratamiento teórico detallado del término confianza. La tercera, se cuestiona la idea de eficacia estatal como causa de la confianza y el modelo de Estado como mecanismo capaz de responder a las complejidades estructurales y regionales de los países de la región y se formulan lúcidos interrogantes para los cuales no tengo respuesta aún, pero que sirven como articuladores de una inquietud genuina en la región y su devenir. Intentaré en los párrafos que siguen responder a tales inquietudes y reflexionar sobre las mismas.

La relación entre capital social y vitalidad democrática a la que refiere Torres, es el motor del afamado trabajo de Putnam (1993) pero también nos remonta a los estudios de cultura cívica de Almond y Verba (1963), donde las orientaciones cognitivas, afectivas y evaluativas hacia el sistema y sus instituciones, el pluralismo, el respeto a la diversidad y el consenso se presentan como requisito de la participación y clave de un funcionamiento exitoso de la democracia. La problematización de tales asuntos nos devuelven la mirada sobre aquellas dimensiones menos institucionales que influyen en la estabilidad y calidad de las democracias y que van más allá de las normas institucionales, sistemas electorales, cuestiones formales o procedimentales de la democracia (Sides, 1999). En esta línea, cabe pensar en la deliberación, entendida como discusión razonada, como un mecanismo de creación de confianza a la vez que herramienta de regeneración de la democracia representativa. Enraizada en el pensamiento republicano, la deliberación y la participación, no solo mejoran la calidad de las decisiones y su legitimidad, sino que permiten el encuentro con el otro y potencialmente el 
desarrollo de un nosotros. En este sentido, la participación y deliberación pueden ser catalizadoras de la confianza a la vez que mecanismos para promover la acción colectiva y reforzar la democracia (Herreros, 2002).

En relación con la definición de confianza utilizada, el trabajo eligió combinar dimensiones: cognitivas, referidas al procesamiento de información contextual (proceso individual y racional); simbólicas, asociadas a imaginarios colectivos y la definición del "nosotros" (elemento social y cultural); e interactivas, vinculadas a las relaciones cara a cara y experiencias de socialización informal (del ámbito de las rutinas y las conductas). Claramente, al definirlo como percepción y no como creencia o actitud, se perdían o solapaban ciertas dimensiones como las afectivas y quizá sea preciso volver sobre ellas en un escenario donde las emociones ocupan el centro del debate académico. Sin embargo, la decisión de tomar a la confianza como percepción resultaba operativa pero además se justificaba porque, tratar a la confianza como creencia o actitud, conducía a pensar en ideas y mapas mentales arraigados y resistentes al cambio y a dimensiones culturales difíciles de capturar y alterar. En cambio, abordarla como una percepción arrojaba una lectura más optimista y daba lugar a trabajar los contextos con la esperanza de trocar aspectos negativos de los mismos y, con ello, mejorar los niveles de confianza. Cuando se observaba la brecha de confianza que exhibían los latinoamericanos en sus países de origen respecto a la que afirmaban tener en países europeos, la hipótesis ganaba fuerza. En su propio país los argentinos o colombianos manifestaban bajos niveles de confianza, pero cuando residían en países europeos sus niveles eran incluso más altos que el de los propios europeos. Era de suponer que, una apreciación y/o evaluación de las señales que arrojaba el nuevo contexto como escenario predecible, seguro y con mayores niveles de eficacia estatal y equidad conducía a cambiar de parecer en relación a la confiabilidad del otro y asumir el nuevo orden social como orden moral superior. No obstante ello, y en vista a los resultados obtenidos, mis actuales investigaciones sobre confianza institucional prestan mayor atención a las dimensiones afectivas de la confianza, al rol de las representaciones sociales, a su funcionalidad social y al "salto de fe" (decisión de suspender la incertidumbre) que supone confiar (Lewis y Weigert, 1985).

Sobre la problemática definición y medición de la eficacia estatal (concepto neoliberal y de raíz economicista) coincido con Torres en su escepticismo. Los índices de eficacia estatal toman en consideración percepciones subjetivas de informantes clave en cada país, con lo cual, el sesgo es inevitable. Además, la mayoría de índices de eficacia sobredimensionan cuestiones relacionadas al libre mercado, altamente volátil y propio de una particular manera de concebir la eficacia estatal. Pese a ello, si se observan diferentes fuentes y medidas de eficacia: como Government Effectiveness (World Bank), Subindex Basic Requirement (World Economic Forum), o State Fragility (Center for Systemic Peace) se encuentran ciertos patrones comunes y este indicador puede servir como aproximación a las capacidades del Estado (Evans, 1996). Estas últimas, se asocian con Estados competentes y enraizados, capaces de garantizar el diseño y la implementación de políticas públicas a la vez que la seguridad y predictibilidad que para Durkheim y otros tantos sociólogos es condición de posibilidad de la vida social. Además, la utilización de estos indicadores, permite producir información sobre la región para luego compararla con otras regiones (Ballart, 2010). En suma, la eficacia estatal (por llamarla de algún modo), sirve como un atajo para problematizar el contexto institucional donde la confianza surge y al Estado como tercera fuerza que interviene penalizando a quienes violan la confianza y enviando mensajes al incumplidor pero también al resto de la sociedad sobre lo que es socialmente deseable y tolerable y lo que no. Castigando con eficacia a quienes violan la confianza, el Estado, además de señalizar lo correcto y proteger la conciencia colectiva y aquellas asunciones 
intangibles que nos aglutinan, preserva al grupo de cumplidores kantianos necesario para la persistencia de la racionalidad colectiva y, con ello, garantiza la cultura de la legalidad y la pervivencia de la cohesión social y la confianza (Nino, 2005; Herreros, 2007).

Por último, Torres formula una serie de interrogantes muy pertinentes sobre el modelo de Estado capaz de suscitar confianza en escenarios de asimetrías regionales para el que no tengo una respuesta clara. Dicha cuestión amerita, y habría que avanzar en ello, un trabajo sobre teoría del Estado y modelos de Estado en contextos de desequilibrios económicos y sociales como muchos de los latinoamericanos. Lo único que me animo a responder es que la distribución equitativa de la riqueza, instrumentada a partir de políticas universales de bienestar implementadas por el Estado central, ha demostrado en otros países ser útil para desarrollar un sentido colectivo compartido, socializar el riesgo individual y fomentar la confianza, a la par que, atenuar las diferencias entre regiones y reducir las desigualdades territoriales. Quizá en la discusión de qué Estado queremos, debamos incluir el debate sobre modelos de políticas sociales o regímenes de bienestar (incluyendo pactos fiscales y regímenes impositivos) que cohesionan el territorio y garantizan, más allá de las diferencias y pluralidad de naciones que se reconozcan dentro de un país, una base social igualitaria.

Por su parte, Virginia Trevignani, desde una perspectiva de sociología cualitativa y recurriendo a un trabajo clásico de la antropología, nos recuerda la importancia de analizar las prácticas sociales, relaciones personales, redes de ayuda mutua y estrategias de adaptación de los grupos sociales. En su intervención sale a relucir: la problemática definición de confianza (que en el libro se aborda como percepción), la selección de la escala y la unidad de análisis, y los potenciales efectos negativos del crecimiento de confianzas particularizadas.

Habiéndome referido ya a la definición de confianza y estando de acuerdo con ella en la pertinencia que tienen los Estados nación incluso en contextos de globalización, me centraré ahora en el desafío a futuro que supone abordar la confianza desde estrategias cualitativas que permitan comprender por qué la gente confía o no y bajo qué condiciones. Una investigación de este tipo, aunque sea difícil de generalizar, se vuelve urgente para complementar los ingentes esfuerzos cuantitativos que en la ciencia política predominaron en los últimos años para explicar las causas y efectos de la confianza. Las prácticas sociales y las redes de ayuda solo pueden desenmarañarse, conocerse e interpretarse en el marco de investigaciones cualitativas y centradas en casos concretos; ojalá en los próximos años pueda complementarse el trabajo aquí reseñado con estudios de tales características en nuestra región.

Asimismo, agradezco que Trevignani destaque la importancia de visibilizar los peligros de la segregación social y urbana, más allá de la ruptura física y social que en sí mismo la hacen condenable (incluso por los economistas liberales). Esto ayuda a entender, no solo aquellos efectos menos tematizados pero igualmente nocivos de la desigualdad, sino también la persistencia en el tiempo de ciertas fracturas e identificar cuellos de botella y trampas desde las cuales a veces se vuelve difícil dar marcha atrás. Como se plantea en el trabajo, la segregación urbana y social se autonomizan de las políticas que las auspiciaron o toleraron y son muy difíciles de revertir, generando sus propias lógicas de reproducción y naturalización social. En lo que al trabajo atañe, el objetivo de los capítulos dedicados al tema era remarcar cómo la segmentación urbana y el desdibujamiento de escenarios de socialización formal pero también informal como la escuela, planteaban serios problemas al encuentro entre desiguales y, por tanto, al desarrollo de una idea sobre 
quiénes somos "nosotros" y quiénes son los "otros". Cuando no existe conciencia de pertenencia a un mismo colectivo imaginario es difícil suponer que las solidaridades florezcan y la confianza se expanda. Por ello, preocuparse y lamentarse por la pérdida o debilitamiento de la confianza social e institucional es contradictorio con una política que deja en manos del mercado la construcción de la ciudad y, por tanto, de la configuración de las relaciones y encuentros dentro de la polis.

Vinculada a lo anterior, Trevignani también se muestra inquieta por el crecimiento de confianzas particularizadas en detrimento de la confianza social y el deterioro que ello supone en términos agregados. Como nos recordaba Carlos Nino "cuanto más fuerte sea la moral particularizada de los grupos sociales, más fácil se hace la cooperación intragrupal y más difícil la cooperación intergrupal" (2005, p. 189).

Estas ideas, latentes también en la sociología durkheimiana, nos remiten a los posteriores trabajos de Bourdieu (2001), quien sostenía cómo el capital social de un grupo puede servir como mecanismo de distinción social y como barrera social para la integración social; y también a las alertas que Portes y Landolt (2000) evidencian en relación a los lazos fuertes de solidaridad y familiaridad como los que se encuentran en la Mafia o entre gánster, que confieren beneficios a sus miembros individuales a expensas del orden público y la paz.

Las solidaridades restringidas y confianzas particularizadas pueden ser importantes para el bienestar de los sujetos en términos individuales, pero vistas desde una perspectiva sociológica, reflejan sociedades con segmentaciones homogéneas y redes endogámicas que dan lugar, recuperando a Tönnies (1979) y Simmel (2002) a múltiples comunidades pero no a sociedades modernas.

Concluyendo, agradezco una vez más a los editores y a las comentaristas por permitirme volver a los clásicos de la sociología y ciencia política para ampliar las miras, a la vez que, devolverme a las problemáticas que atraviesa actualmente una región como la latinoamericana en relación a la democracia, la sociabilidad y el Estado. "Confío" que varias de las preocupaciones aquí planteadas den lugar a nuevos trabajos y reflexiones sobre la materia y, con el tiempo, podamos comprender mejor las causas de la confianza y los efectos de la acción estatal en la misma para alcanzar esos deseados niveles de bienestar que con tanta ansia busca América Latina.

\section{Bibliografía}

Almond, G., \& Verba, S. (1963), The Civic Culture: Political Attitudes and Democracy in Five Nations, New Jersey, Princeton.

BALLART, X. (2010), "Una presa difícil de atrapar: el rendimiento de gobiernos y administraciones públicas", Revista Española de Ciencia Política, n² 22, pp. 11-28.

BouRdieu, P. (2001), "El capital social. Apuntes provisionales", Zona Abierta (94/95), pp. 83-87.

Evans, P. (1996), "Government Action, Social Capital and Development: Reviewing the Evidence on Synergy", World Development, 24 (6), pp. 1119-1132.

HerReros, F. (2002), "Republicanismo, Capital Social y Democracia", Revista de Estudios Políticos (Nueva época), n 117, pp. 293-312. 
HeRREROS, F. (2007). "Confianza y cooperación en ausencia de Estado", Revista Internacional De Sociología, LXV (46), 161-183.

LEWIS, D., \& WeIGERT, A. (1985). "Trust as a Social Reality", Social Force, 63 (4), 967-985.

NinO, C. (2005 reimp. [1993]). Un país al margen de la ley, Buenos Aires, Ariel.

Portes, A., \& LANDOlt, P. (2000). "Social Capital: Promise and Pitfalls of Its Role in Development”, Journal of Latin American Studies, 32 (2), 529-547.

Putnam, R. (1993). Making Democracy Work. Civic traditions in Modern Italy, Princeton, Princeton University Press.

SIDES, J. (1999). "It takes two: The reciprocal relationship between Social Capital and Democracy". Working Paper Institute of Governmental Studies, University of California.

SIMMEL, G. (2002). Sobre la Individualidad y las formas sociales. Escritos Escogidos. Buenos Aires, Universidad Nacional de Quilmes.

TÖNNIES, F. (1979). Comunidad y Asociación. Barcelona, Ediciones Panínsula 